\title{
Synthesis and Characterization of Zinc Oxide and Iron Oxide Nanoparticles Using Sesbania grandiflora Leaf Extract as Reducing Agent
}

\author{
Sorna Prema Rajendran and Kandasamy Sengodan \\ Department of Food Technology, Kongu Engineering College, Perundurai 638 052, India \\ Correspondence should be addressed to Sorna Prema Rajendran; sornarajendran42@gmail.com
}

Received 22 June 2016; Accepted 18 December 2016; Published 3 January 2017

Academic Editor: Sanjeeb K. Sahoo

Copyright (C) 2017 S. P. Rajendran and K. Sengodan. This is an open access article distributed under the Creative Commons Attribution License, which permits unrestricted use, distribution, and reproduction in any medium, provided the original work is properly cited.

\begin{abstract}
The objectives of this present study are to synthesize iron oxide and zinc oxide nanoparticles from different concentrations of Sesbania grandiflora leaf extract (5-20\%) using zinc nitrate and ferrous chloride as precursor materials and synthesized nanoparticles were characterized using UV-visible spectrometer, FTIR, X-ray diffraction, and SEM. The results showed that synthesized zinc oxide and iron oxide nanoparticles exhibited UV-visible absorption peaks at $235 \mathrm{~nm}$ and $220 \mathrm{~nm}$, respectively, which indicated that both nanoparticles were photosensitive and the XRD study confirmed that both nanoparticles were crystalline in nature. In addition, FTIR was also used to analyze the various functional groups present in the synthesized nanoparticles. The SEM results reveal that zinc oxide nanoparticles were spherical in shape and having the particle size range of 15 to $35 \mathrm{~nm}$ whereas the iron oxide nanoparticles were nonspherical in shape with the size range of 25 to $60 \mathrm{~nm}$. Application of synthesized nanoparticle on seafood effluent treatment was studied.
\end{abstract}

\section{Introduction}

In the last decade biosynthesis of metal oxide nanoparticles has received increasing attention due to their potential properties such as optical, electronic, mechanical, magnetic, and chemical properties and hence has incredible applications in the field of physics, chemistry, medicine, biology, agriculture, food processing, and so forth [1]. Wide varieties of methods have been reported for synthesis of zinc oxide and iron oxide nanoparticles such as coprecipitation technique [2], thermal decomposition methods [3], hydrothermal technique [4], sol gel method [5], and electrochemical methods [6]. However these methods are energy consuming, using hazardous solvents and expensive reagents in their preparation $[7,8]$; therefore the rising needs to develop eco-friendly green method for nanoparticle preparation [9]. Recently plant mediated green synthesis of different nanoparticles from various plants such as Cassia alata [10], Camellia sinensis [11], Mangifera indica [12], Azadirachta indica [13], Syzygium cumini [14], and Ocimum basilicum [15] has been reported.
Sesbania grandiflora belongs to the family of Fabaceae and commonly known as agati in Tamil and humming bird tree in English, leaf of the plant consumed as a green leaf vegetable in India. All the parts of plant are widely used in traditional Ayurvedic medicine to treat the broad spectrum of disease including tumor, liver disorder, constipation, intestine inflammation, urinary infection, and intestine inflammation [16]. The leaves are good source of phytochemicals such as phenolic acids, polyphenol, and flavanoid [17].

An extensive literature survey shows that there is no research report available for synthesis of zinc oxide and iron oxide nanoparticle using commercially available Sesbania grandiflora leaf extract, so that the present study discusses the plant mediated green synthesis of zinc oxide and iron oxide nanoparticles using Sesbania grandiflora leaf extract which is used as a reducing agent to convert the precursors into nanoparticles. In addition to that the synthesized nanoparticles are characterized with the aid of UV-visible spectrometer, Fourier transform infrared spectroscopy, X-ray diffractometer, and scanning electron microscope. 


\section{Materials and Methods}

2.1. Raw Material. Zinc nitrate and ferrous chloride were purchased from, Hi Media, India. Sesbania grandiflora leaves were obtained from the local market near Perundurai, Tamil Nadu, India. All the chemicals used in this study were analytical grade.

2.2. Preparation of Leaf Extract. The fresh leaves were washed with running tap water in order to remove the impurities adhering on the surface of the leaves. Then the leaves gently were wiped by the filter paper, known amount of leaves (5$20 \mathrm{~g}$ ) was added to $250 \mathrm{ml}$ beaker, and $100 \mathrm{ml}$ distilled water was added and kept at $60^{\circ} \mathrm{C}$ in a temperature controlled hot plate until the color of the water was turned to green color. Then the extract was cooled at room temperature, filtered (Whatman number 1 filter paper), and stored for further experimental analysis.

2.3. Preparation of Nanoparticles. A known amount of $(50 \mathrm{ml})$ filtered leaf extract of different concentrations was taken in the beakers and heated at $60^{\circ} \mathrm{C}$ in a temperature controlled hot plate. Then $5 \mathrm{~g}$ of precursor (zinc nitrate for zinc oxide nanoparticles and ferrous chloride for iron oxide nanoparticles) was added to the heated leaf extract and stirred well using a glass rod until the mixture was turned to paste form (yellow color: zinc oxide nanoparticle, black color: iron oxide). The paste was collected carefully in ceramic crucibles and kept in a muffle furnace at $500^{\circ} \mathrm{C}$ for $2 \mathrm{~h}$ in order to remove the organic impurities present in the paste. After $2 \mathrm{~h}$, the synthesized nanoparticles present in the crucible were taken and stored in an airtight container for future experimental work.

2.4. Characterization of Nanoparticles. The characterization of the synthesized nanoparticles from different concentrations of Sesbania grandiflora leaf extracts using precursors (zinc nitrate and ferrous chloride) was characterized using UV-visible spectrometer, FTIR, X-ray diffraction, and scanning electron microscopy. Optical properties of synthesized nanoparticles were examined using double beam UV-visible spectrometer (Elico spectral treats version 2.2) with a spectral range of $190-400 \mathrm{~nm}$. Functional groups present in the synthesized nanoparticles were found by FTIR spectrometer (Shimadzu) at a region of $4000 \mathrm{~cm}^{-1}$ to $400 \mathrm{~cm}^{-1}$ using $\mathrm{KBr}$ pellet method with a resolution of $4 \mathrm{~cm}^{-1}$. X-ray diffraction pattern was obtained from Seifert XRD 3003 diffractometer having the $\mathrm{Cu}-\mathrm{K}_{\alpha}$ radiation source which was used to confirm the presence of green synthesized nanoparticles. The samples were scanned in the $2 \theta$ ranges of 10 to $70^{\circ} \mathrm{C}$ with the scan rate of $0.04^{\circ} / \mathrm{sec}$ and the average particle size was also to be calculated from the diffractogram using Debye-Scherrer's formula [18]. The structural morphology of prepared nanoparticles was carried out by JSM 6360 scanning electron microscope with an accelerating voltage between 10 and $20 \mathrm{KV}$ under the vacuum condition.

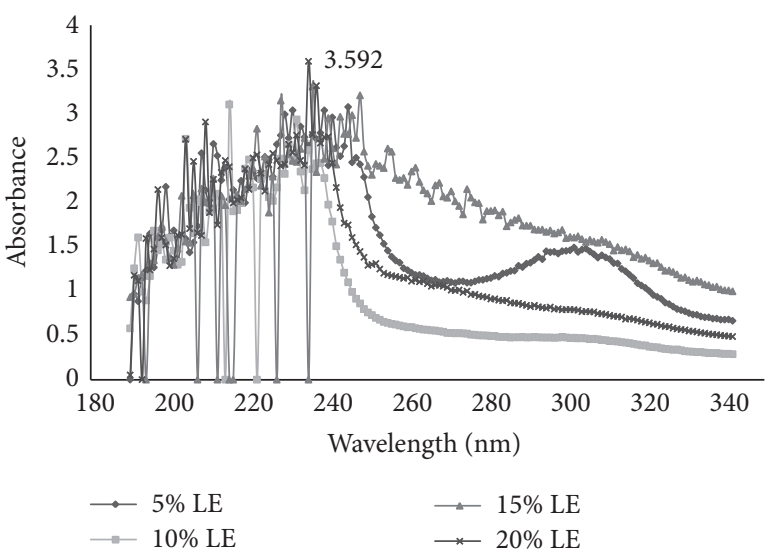

FIGURE 1: UV-visible spectrum for $\mathrm{ZnO}$ nanoparticles.

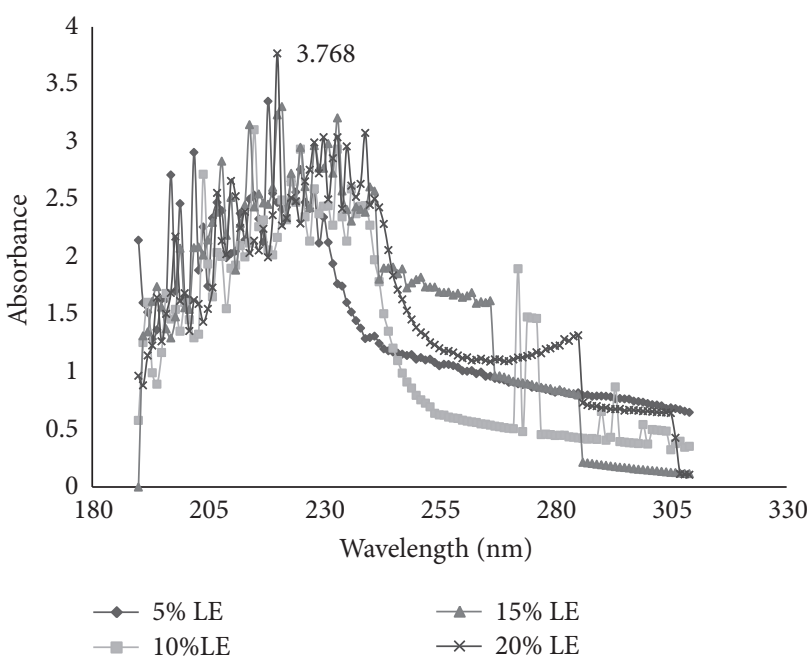

FIgURE 2: UV-visible spectrum for $\mathrm{Fe}_{3} \mathrm{O}_{4}$ nanoparticles.

\section{Results and Discussions}

3.1. UV-Visible Spectroscopy. Nanoparticles were prepared using different leaf extract concentrations (5-20\%), characterized using UV-visible spectrometer, and the results were shown in Figures 1 and 2. From the results, it was observed that maximum absorption peak was found at $235 \mathrm{~nm}$ for zinc oxide nanoparticles and $220 \mathrm{~nm}$ for iron oxide nanoparticles, respectively. This could be due to the excitation of nanoparticles from ground state to excited state [8]. The increasing concentration of leaf extract enhanced the phytochemical content of the extract and it can reduce the precursor quickly which leads to increasing the formation of nanoparticles rapidly and enhancing the absorbance value [19].

Actual band gap wavelength of zinc oxide and iron oxide was $388 \mathrm{~nm}$ and $370 \mathrm{~nm}$, respectively, which was higher than $235 \mathrm{~nm}$ and $220 \mathrm{~nm}$ (Figures 1 and 2) which may be due to agglomeration and settling of nanoparticles in a cuvette which cause decreasing the absorption of radiation. Similar kind of result was found by [20] synthesizing the zinc oxide nanoparticles by micro emulsion method. 


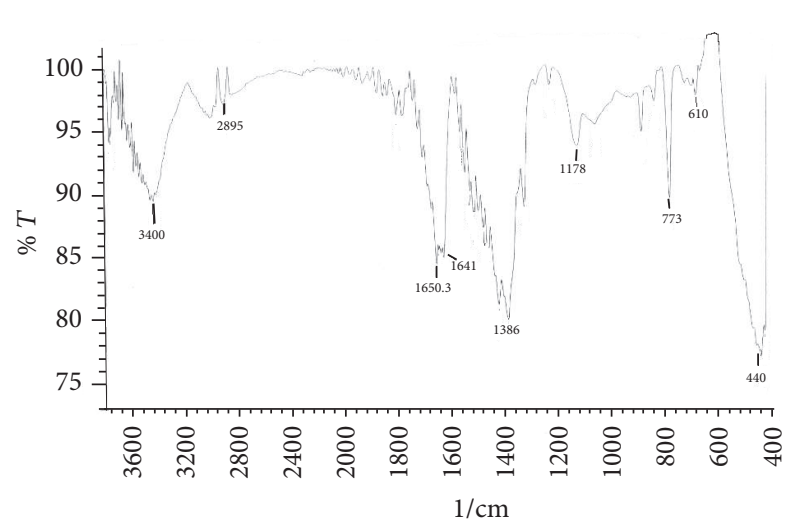

FIgURE 3: FTIR spectrum for zinc oxide nanoparticles.

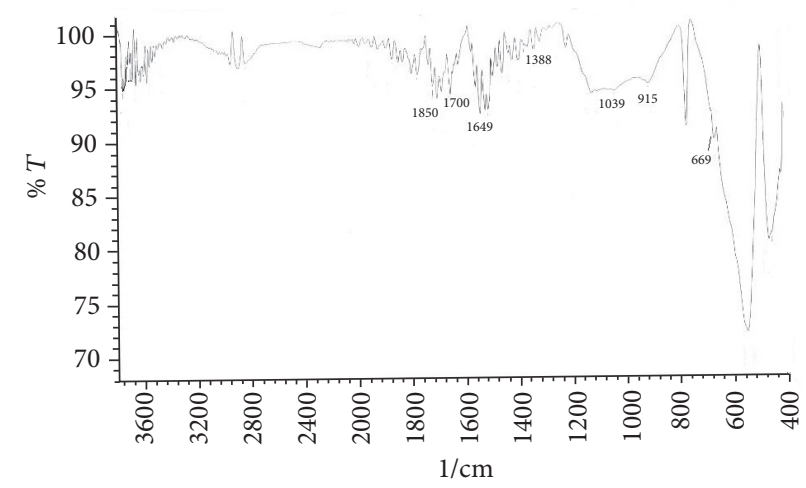

FigURE 4: FTIR spectrum for $\mathrm{Fe}_{3} \mathrm{O}_{4}$ nanoparticles.

From the UV-visible spectrometer analysis concluded that zinc oxide and iron oxide nanoparticles had an intense absorbance at $\sim 250 \mathrm{~nm}$ which indicates that the synthesized particles were photosensitive in UV region [21].

3.2. FTIR Spectrometer. The synthesized iron and zinc oxide nanoparticles from leaf extract (20\%) were analyzed by FTIR spectroscopy technique in order to find out the functional groups present in the particles. Bandwidth of $1500-600 \mathrm{~cm}^{-1}$ exhibited the fingerprint region of zinc oxide nanoparticles [22]. Strong peak observed at the frequency of $1650 \mathrm{~cm}^{-1}$ indicates the $\mathrm{N}-\mathrm{H}$ bending and weak peaks were found at $1508 \mathrm{~cm}^{-1}$ and $1641 \mathrm{~cm}^{-1}$ (Figure 3) assigned to symmetric and asymmetric vibration of $\mathrm{C}=\mathrm{O}$ [23]. The broad peak around $3400 \mathrm{~cm}^{-1}$ showed the $\mathrm{OH}$ stretching bond vibration which was due to the water adsorption on the surface of zinc oxide nanoparticles [24] while the peak at $440 \mathrm{~cm}^{-1}$ (Figure 3) was attributed to the $\mathrm{Zn}-\mathrm{O}$ stretching vibration.

Various compounds associated with iron oxide nanoparticles were characterized by FTIR spectrum and it was illustrated in Figure 4. The peaks at $1700 \mathrm{~cm}^{-1}$ and $1850 \mathrm{~cm}^{-1}$ exhibited the $\mathrm{C}=\mathrm{O}$ stretching vibrations [25] and the strong peak at 1388 indicated the aromatic amine $(\mathrm{C}-\mathrm{N})$ stretching and the medium peak at $915 \mathrm{~cm}^{-1}$ assigned to carboxylic acid $(\mathrm{O}-\mathrm{H})$ bending vibrations. The peak was found at a frequency of $669 \mathrm{~cm}^{-1}$ due to $\mathrm{Fe}-\mathrm{O}$ bond vibration [26]. The peaks at

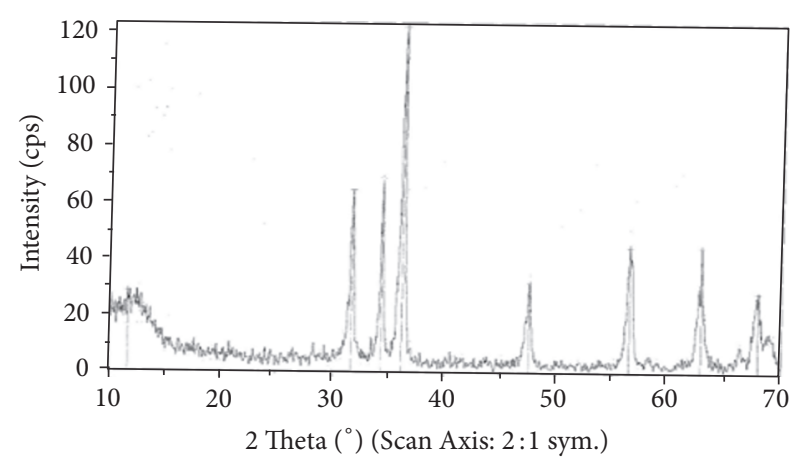

FIGURE 5: XRD pattern of zinc oxide nanoparticles.

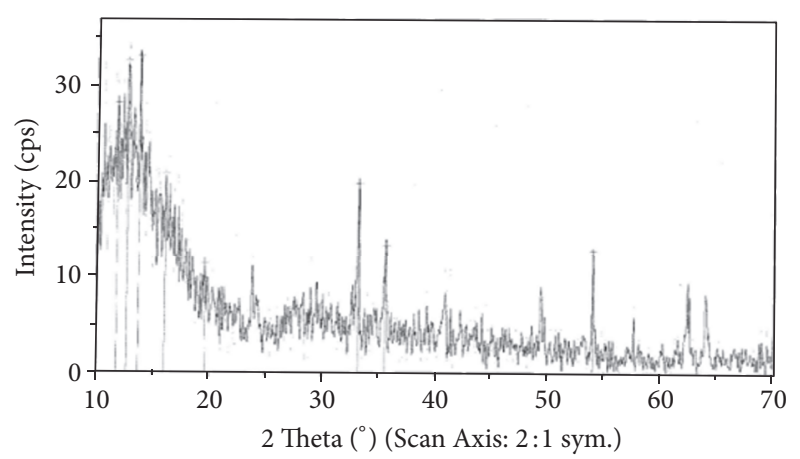

FIGURE 6: XRD pattern of $\mathrm{Fe}_{3} \mathrm{O}_{4}$ nanoparticles.

$1649 \mathrm{~cm}^{-1}$ and $1039 \mathrm{~cm}^{-1}$ were corresponding to the $>\mathrm{C}=\mathrm{O}$ asymmetric stretching and $\mathrm{COO}^{-}$symmetric stretching [27].

3.3. X-Ray Diffraction. Synthesized zinc oxide and iron oxide nanoparticles from $20 \%$ leaf extract concentration were characterized using $\mathrm{Cu}-\mathrm{K} \alpha \mathrm{X}$-ray diffractometer for confirming the presence of nanoparticles and analyzing its structure which was shown in Figures 5 and 6, respectively. From the result (Figure 5) the peaks were identified at $31.77^{\circ}, 34.44^{\circ}$, $36.28^{\circ}, 47.60^{\circ}, 56.52^{\circ}, 62.88^{\circ}$, and $67.96^{\circ}$. These peaks were in well agreement with the literature report of $[20,28]$ and also well consistent with the JCPDS file card number 01-075-0576 thus showing the synthesized nanoparticles were identical to hexagonal phase of zinc oxide [29].

Similarly the X-ray diffraction pattern of iron oxide nanoparticles was illustrated in Figure 6. Peaks were found in a diffractogram at an angle of $18.44^{\circ}, 19.60^{\circ}, 23.84^{\circ}, 33.20^{\circ}$, $35.64^{\circ}, 40.96^{\circ}, 49.44^{\circ}, 54^{\circ}$, and $62.60^{\circ}$ which indicated that the synthesized iron oxide nanoparticles were crystalline phase and also result was well matched with the JCPDS card number 19-0629 [30]. Similar kinds of results have been found in green synthesis of manetite nanoparticle [31].

3.4. Scanning Electron Microscope. SEM analysis was carried out to find the surface morphology of zinc oxide and iron nanoparticles prepared from $20 \%$ leaf extract concentration using JSM-6360 scanning electron microscope at different magnification levels and results were shown in Figures 7 and 8 , respectively. The micrographs (Figures 7 and 8) showed 

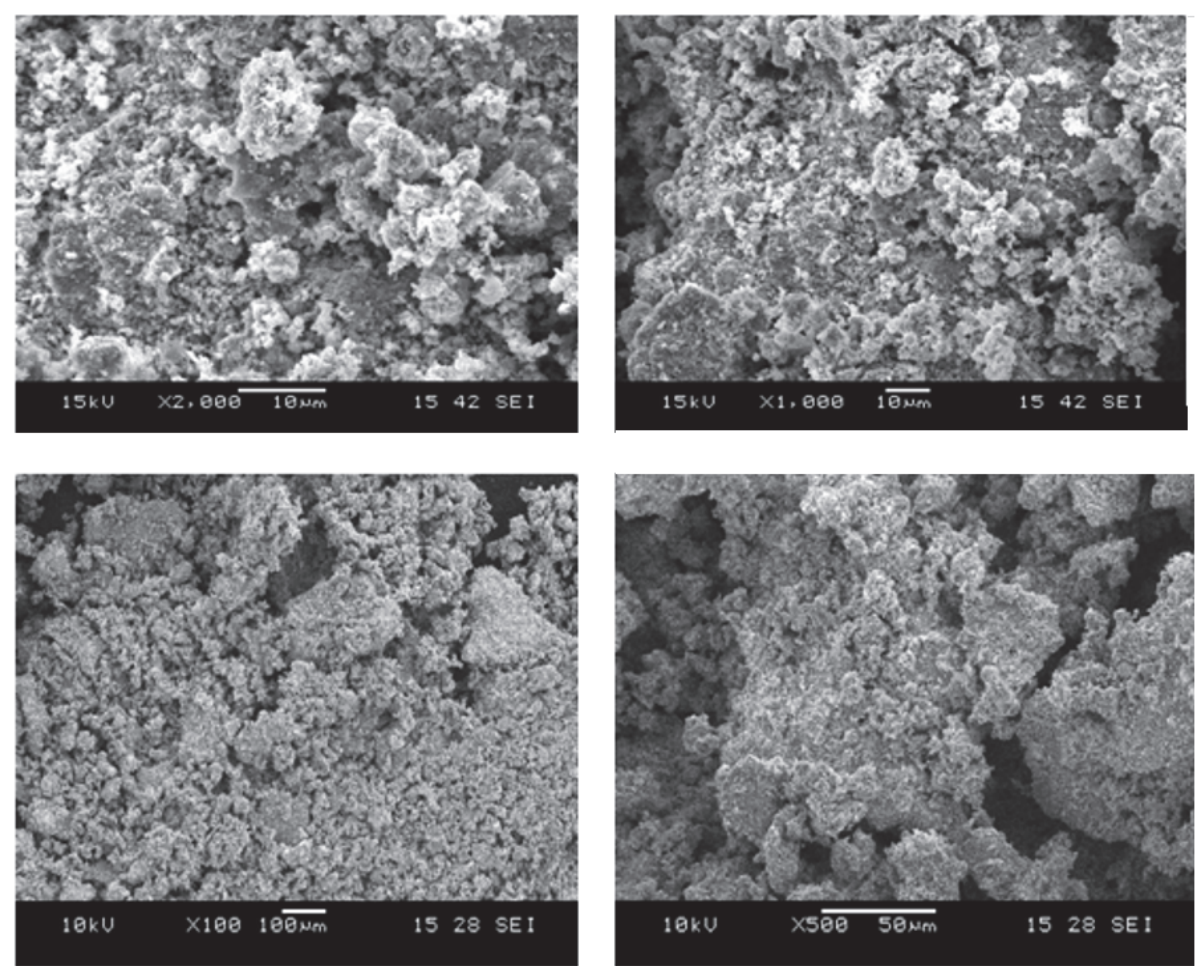

FIGURE 7: SEM image of zinc oxide nanoparticles.
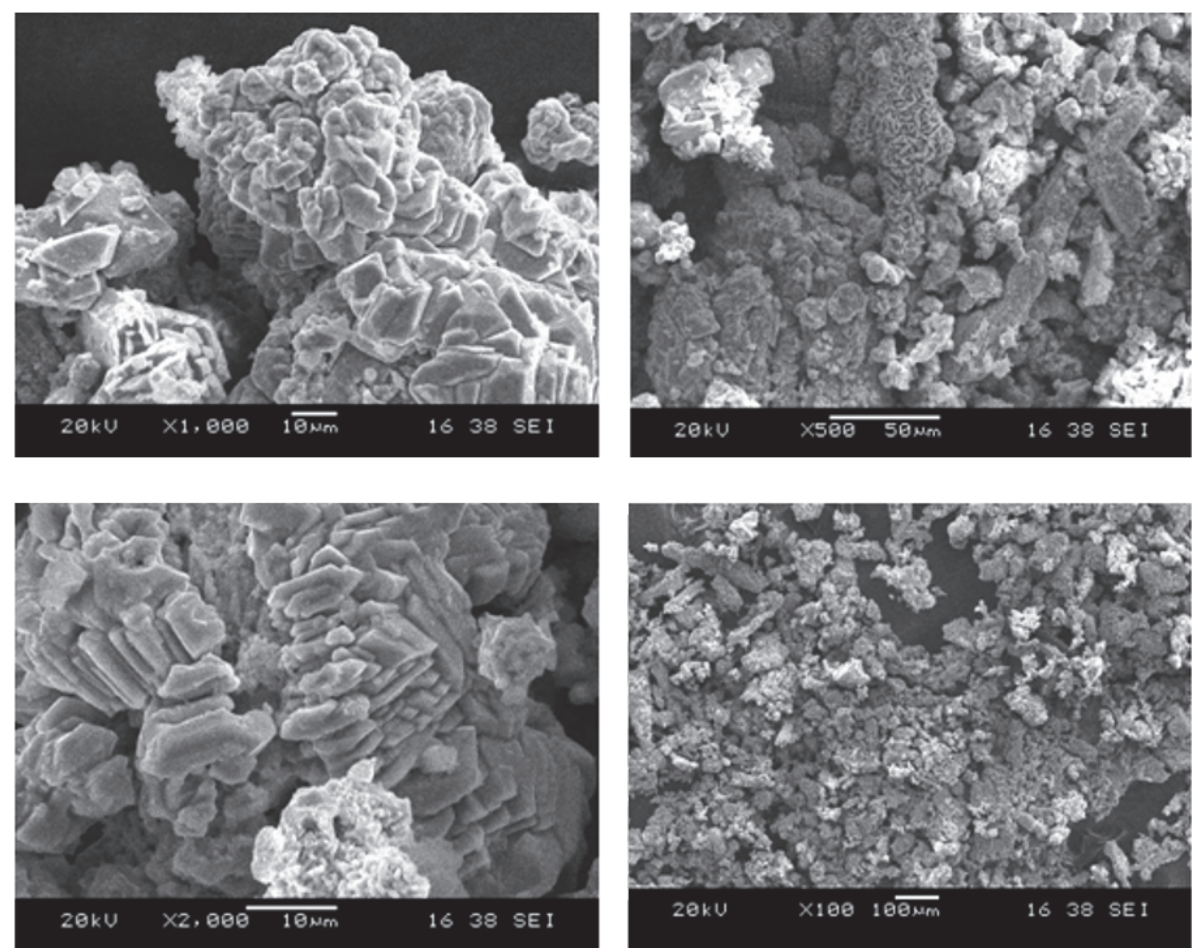

Figure 8: SEM image of $\mathrm{Fe}_{3} \mathrm{O}_{4}$ nanoparticles. 


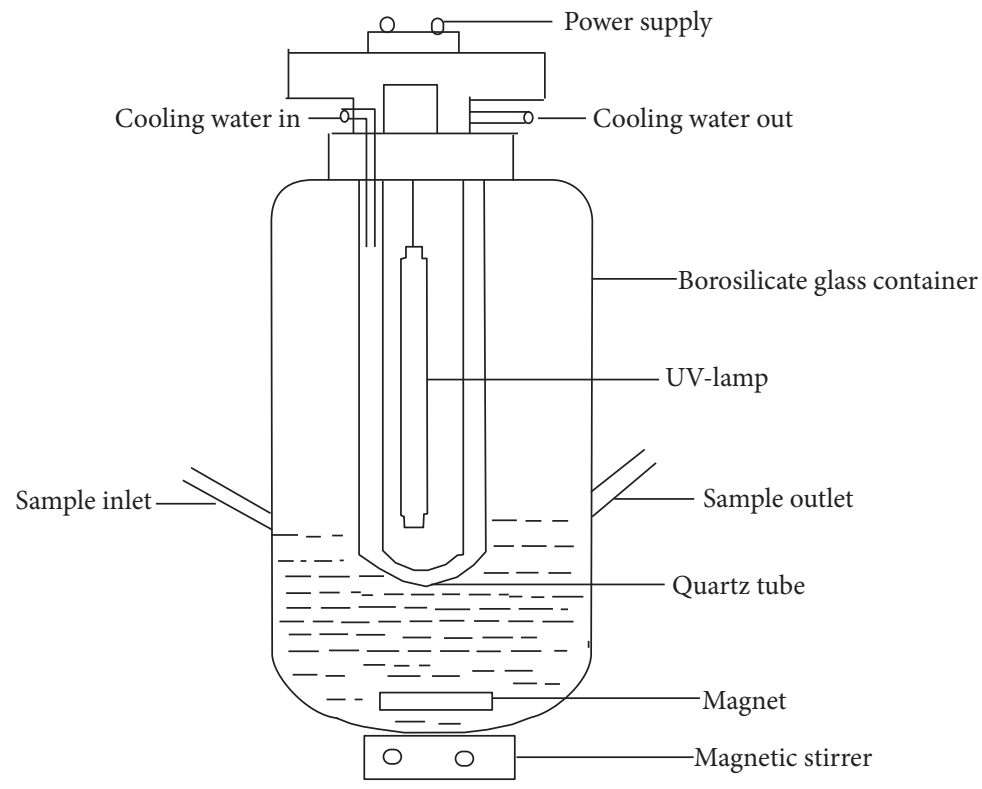

FIgURE 9: Photocatalytic reactor.
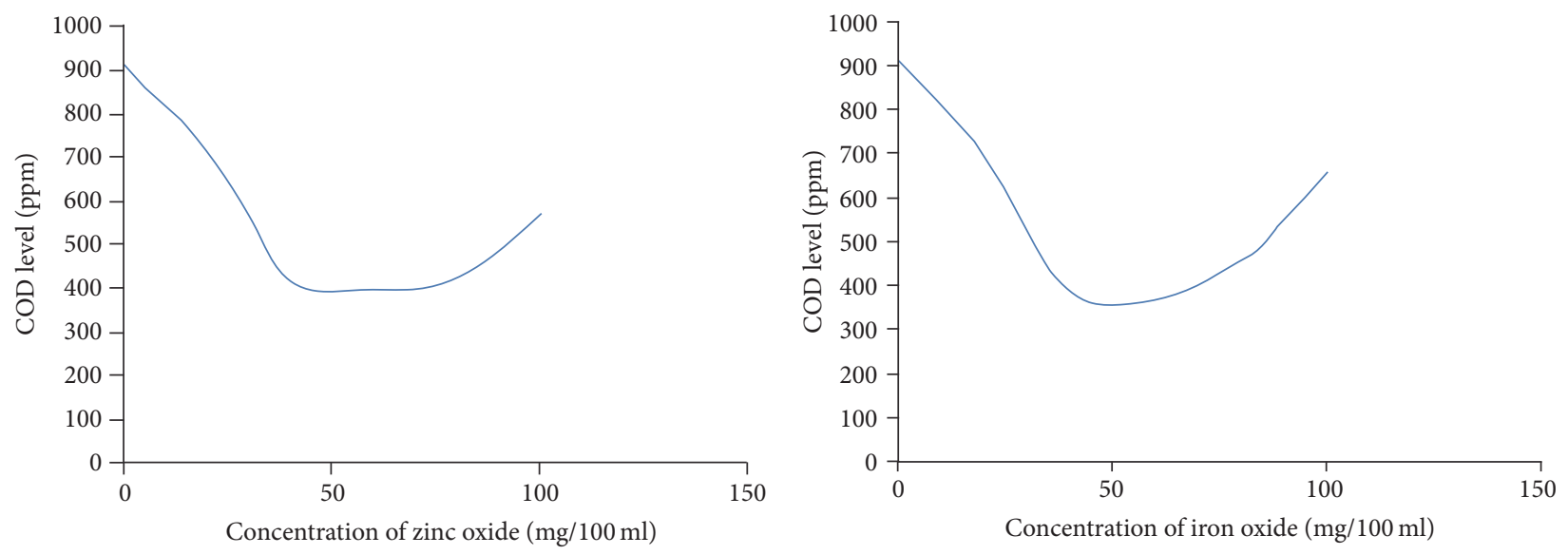

FIGURE 10: Effect of zinc oxide and iron oxide on COD level.

that the network formation occurred at the zinc oxide and iron oxide nanoparticles. It was clearly indicated that the agglomeration had been taken place. From the images it was confirmed that the synthesized zinc oxide and iron oxide nanoparticles were in well agreement with the result obtained from XRD. Moreover the synthesized zinc oxide nanoparticles had a spherical shape and iron oxide nanoparticles were nonspherical shapes with rough surface.

\section{Application}

Prepared zinc oxide and iron oxide nanocatalyst are excellent photocatalytic oxidation material used for treating industrial effluent $[32,33]$. In the current research, it could be used to remove the organic pollutant present in the sea food industry effluent treatment. Initial chemical oxygen demand (COD) of sea food industry effluent is 912 ppm. Effluent was taken from an industry located at Tuticorin, Tamil Nadu, India, and stored at $4^{\circ} \mathrm{C} .100 \mathrm{ml}$ of effluent was taken in a photocatalytic reactor which is shown in Figure 9. A known quantity of photocatalytic material was added to the effluent after a particular treatment time; the effluent was taken and COD was measured.

Figure 10 represents the effect of zinc oxide and iron oxide nanoparticles on COD level. Initially the COD level was reduced gradually; it was due to production of more hydroxyl radical which degrades organic pollutant; after certain dosage COD level starts to increase; it might be due to opaqueness created by nanoparticles which prevent the light penetration that leads to lower production of hydroxyl radical.

\section{Conclusion}

Green synthesis of zinc oxide and iron oxide nanoparticles using Sesbania grandiflora leaf extract provides an effective route for eco-friendly method of synthesis of nanoparticles. 
These materials seem to possess different morphology and structural properties and the SEM analysis showed that the aggregation and network formation of nanoparticles had been taking place. It was found that increasing the leaf extract concentration increases the rate of reduction and the reduction of precursor into the nanoparticles to be optimized at $20 \%$ leaf extract concentration. Both zinc oxide and iron oxide nanoparticles could be used as a better source as a photocatalyst for COD removal.

\section{Competing Interests}

The authors do not have any conflict of interests with the contents in the paper.

\section{Acknowledgments}

The authors are thankful to Dr. J. Prakash Maran, Assistant Professor, Department of Food Technology, Kongu Engineering College, for his guidance in interpreting graphical results and writing research paper.

\section{References}

[1] M. Sathishkumar, K. Sneha, S. W. Won, C.-W. Cho, S. Kim, and Y.-S. Yun, "Cinnamon zeylanicum bark extract and powder mediated green synthesis of nano-crystalline silver particles and its bactericidal activity," Colloids and Surfaces B: Biointerfaces, vol. 73, no. 2, pp. 332-338, 2009.

[2] A. K. Gupta and M. Gupta, "Synthesis and surface engineering of iron oxide nanoparticles for biomedical applications," Biomaterials, vol. 26, no. 18, pp. 3995-4021, 2005.

[3] L. Song, S. Zhang, B. Chen, J. Ge, and X. Jia, "A hydrothermal method for preparation of $\alpha-\mathrm{Fe}_{2} \mathrm{O}_{3}$ nanotubes and their catalytic performance for thermal decomposition of ammonium perchlorate," Colloids and Surfaces A: Physicochemical and Engineering Aspects, vol. 360, no. 1-3, pp. 1-5, 2010.

[4] H. Hayashi and Y. Hakuta, "Hydrothermal synthesis of metal oxide nanoparticles in supercritical water," Materials, vol. 3, no. 7, pp. 3794-3817, 2010.

[5] J. S. Kim, E. Kuk, K. N. Yu et al., "Antimicrobial effects of silver nanoparticles," Nanomedicine: Nanotechnology, Biology, and Medicine, vol. 3, no. 1, pp. 95-101, 2007.

[6] A. A. Ensafi, H. Karimi-Maleh, M. Ghiaci, and M. Arshadi, "Characterization of Mn-nanoparticles decorated organofunctionalized $\mathrm{SiO}_{2}-\mathrm{Al}_{2} \mathrm{O}_{3}$ mixed-oxide as a novel electrochemical sensor: application for the voltammetric determination of captopril," Journal of Materials Chemistry, vol. 21, no. 38, pp. 15022-15030, 2011.

[7] J. Das, M. P. Das, and P. Velusamy, "Sesbania grandiflora leaf extract mediated green synthesis of antibacterial silver nanoparticles against selected human pathogens," Spectrochimica Acta Part A: Molecular and Biomolecular Spectroscopy, vol. 104, pp. 265-270, 2013.

[8] H. R. Naika, K. Lingaraju, K. Manjunath et al., "Green synthesis of $\mathrm{CuO}$ nanoparticles using Gloriosa superba L. extract and their antibacterial activity," Journal of Taibah University for Science, vol. 9, no. 1, pp. 7-12, 2015.
[9] A. Leela and M. Vivekanandan, "Tapping the unexploited plant resources for the synthesis of silver nanoparticles," African Journal of Biotechnology, vol. 7, no. 17, pp. 3162-3165, 2008.

[10] S. A. Gaddam, V. S. Kotakadi, D. S. Gopal, Y. S. Rao, and A. V. Reddy, "Efficient and robust biofabrication of silver nanoparticles by cassia alata leaf extract and their antimicrobial activity," Journal of Nanostructure in Chemistry, vol. 4, no. 1, pp. $1-9,2014$

[11] S. S. K. Kamal, P. K. Sahoo, J. Vimala, M. Premkumar, S. Ram, and L. Durai, "A novel green chemical route for synthesis of silver nanoparticles using Camellia Sinensis," Acta Chimica Slovenica, vol. 57, no. 4, pp. 808-812, 2010.

[12] M. Pattanayak and P. L. Nayak, "Ecofriendly green synthesis of iron nanoparticles from various plants and spices extract," International Journal of Plant, Animal and Environmental Sciences, vol. 3, no. 1, pp. 68-78, 2013.

[13] M. Pattanayak and P. L. Nayak, "Green synthesis of gold nanoparticles using Elettaria cardamomum (ELAICHI) aqueous extract," World Journal of Nano Science Technology, vol. 21, p. 6, 2013.

[14] J. Banerjee and R. T. Narendhirakannan, "Biosynthesis of silver nanoparticles from Syzygium cumini (L.) seed extract and evaluation of their in vitro antioxidant activities," Digest Journal of Nanomaterials and Biostructures, vol. 6, pp. 961-968, 2011.

[15] H. Abdul Salam, R. Sivaraj, and R. Venckatesh, "Green synthesis and characterization of zinc oxide nanoparticles from Ocimum basilicum L. var. purpurascens Benth.-Lamiaceae leaf extract," Materials Letters, vol. 131, pp. 16-18, 2014.

[16] S. Sreelatha, P. R. Padma, and E. Umasankari, "Evaluation of anticancer activity of ethanol extract of Sesbania grandiflora (Agati Sesban) against Ehrlich ascites carcinoma in Swiss albino mice," Journal of Ethnopharmacology, vol. 134, no. 3, pp. 984987, 2011.

[17] K. Padmalochana and M. D. Rajan, "Antimicrobial activity of Aqueous, Ethanol and Acetone extracts of Sesbania grandiflora leaves and its phytochemical characterization," International Journal of Pharma Sciences and Research, vol. 5, no. 12, p. 957, 2015.

[18] M. Ahamed, H. A. Alhadlaq, M. A. M. Khan, P. Karuppiah, and N. A. Al-Dhabi, "Synthesis, characterization, and antimicrobial activity of copper oxide nanoparticles," Journal of Nanomaterials, vol. 2014, Article ID 637858, 4 pages, 2014.

[19] R. S. R. Isaac, G. Sakthivel, and C. Murthy, "Green synthesis of gold and silver nanoparticles using Averrhoa bilimbi fruit extract," Journal of Nanotechnology, vol. 2013, Article ID 906592, 6 pages, 2013.

[20] H. Kumar and R. Rani, "Structural and optical characterization of $\mathrm{ZnO}$ nanoparticles synthesized by microemulsion route," International Letters of Chemistry, Physics and Astronomy, vol. 19, pp. 26-36, 2013.

[21] M. Savi, S. Rossi, L. Bocchi et al., "Titanium dioxide nanoparticles promote arrhythmias via a direct interaction with rat cardiac tissue," Particle and Fibre Toxicology, vol. 11, no. 1, article 63, 2014.

[22] M. R. Vaezi and S. K. Sadrnezhaad, "Nanopowder synthesis of zinc oxide via solochemical processing," Materials and Design, vol. 28, no. 2, pp. 515-519, 2007.

[23] S. Husain, F. Rahman, N. Ali, and P. A. Alvi, "Nickel sub-lattice effects on the optical properties of $\mathrm{ZnO}$ nanocrystals," Journal of Optoelectronics Engineering, vol. 1, no. 1, pp. 28-32, 2013.

[24] G. Xiong, U. Pal, J. G. Serrano, K. B. Ucer, and R. T. Williams, "Photoluminesence and FTIR study of $\mathrm{ZnO}$ nanoparticles: the 
impurity and defect perspective," Physica Status Solidi (C), vol. 3, no. 10, pp. 3577-3581, 2006.

[25] T. Shahwan, S. Abu Sirriah, M. Nairat et al., "Green synthesis of iron nanoparticles and their application as a Fenton-like catalyst for the degradation of aqueous cationic and anionic dyes," Chemical Engineering Journal, vol. 172, no. 1, pp. 258-266, 2011.

[26] B. Kumar, K. Smita, L. Cumbal, and A. Debut, "Biogenic synthesis of iron oxide nanoparticles for 2-arylbenzimidazole fabrication," Journal of Saudi Chemical Society, vol. 18, no. 4, pp. 364-369, 2014.

[27] P. R. Kumar, Y. H. Jung, K. K. Bharathi, C. H. Lim, and D. K. Kim, "High capacity and low cost spinel $\mathrm{Fe}_{3} \mathrm{O}_{4}$ for the Na-ion battery negative electrode materials," Electrochimica Acta, vol. 146, pp. 503-510, 2014.

[28] R. Sharmila Devi and R. Gayathri, "Green synthesis of zinc oxide nanoparticles by using hibiscus rosa-sinensis," International Journal of Current Engineering and Technology, vol. 4, no. 4, pp. 2444-2446, 2014.

[29] N. F. Hamedani and F. Farzaneh, "Synthesis of $\mathrm{ZnO}$ nanocrystals with hexagonal (Wurtzite) structure in water using microwave irradiation," Journal of Sciences, Islamic Republic of Iran, vol. 17, no. 3, pp. 231-234, 2006.

[30] P. D. File, JCPDS International Center for Powder Diffraction Data, Swarthmore College, Swarthmore, Pa, USA, 1989.

[31] A. M. Awwad and N. M. Salem, "A green and facile approach for synthesis of magnetite nanoparticles," Nanoscience and Nanotechnology, vol. 2, no. 6, pp. 208-213, 2012.

[32] Z. Meng and Z. Juan, "Wastewater treatment by photocatalytic oxidation of Nano-ZnO," Global Environmental Policy in Japan, vol. 12, pp. 1-9, 2008.

[33] E. E. Ebrahiem, M. N. Al-Maghrabi, and A. R. Mobarki, "Removal of organic pollutants from industrial wastewater by applying photo-Fenton oxidation technology," Arabian Journal of Chemistry, 2013. 

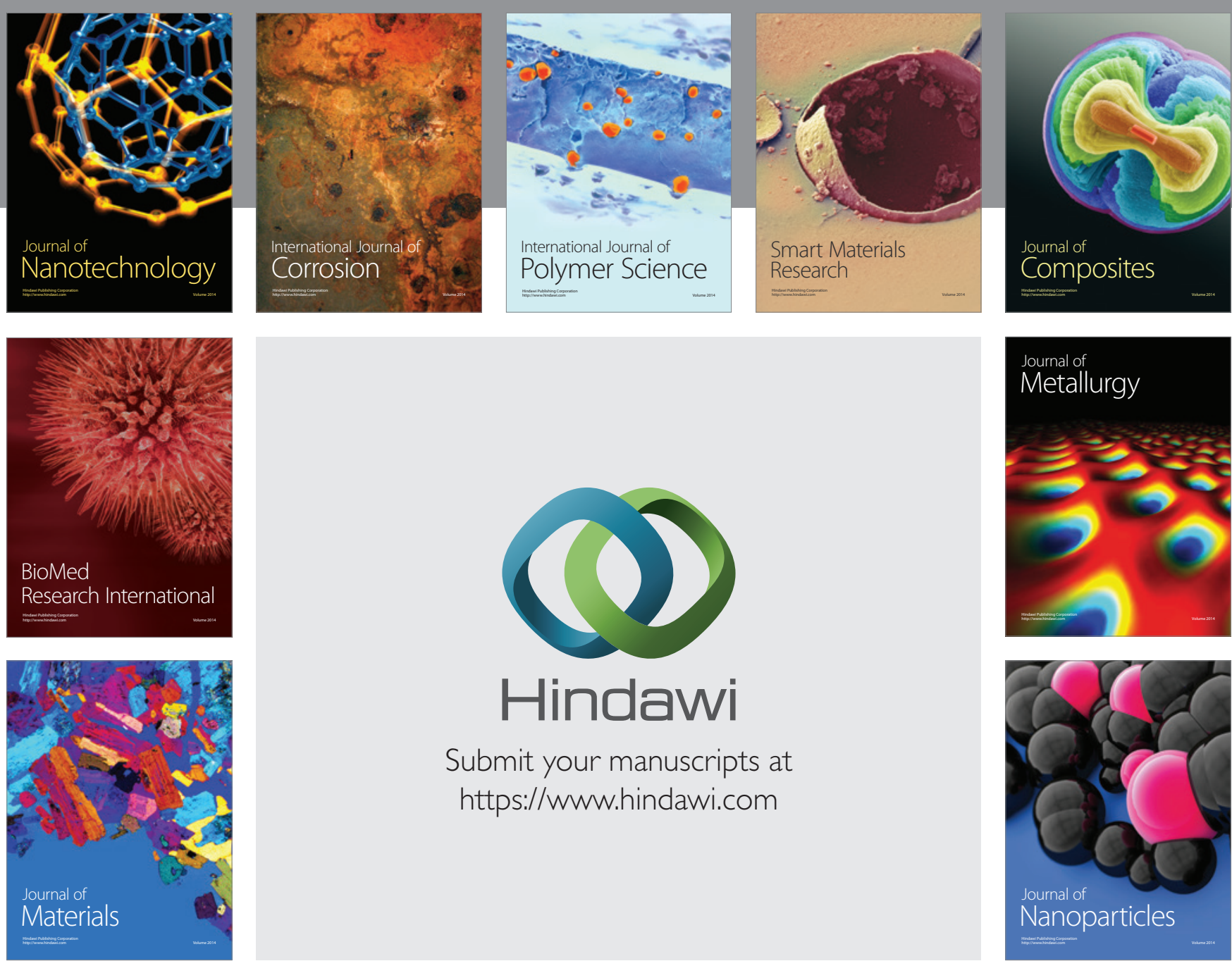

\section{Hindawi}

Submit your manuscripts at

https://www.hindawi.com

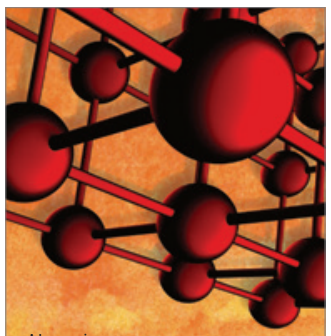

Materials Science and Engineering
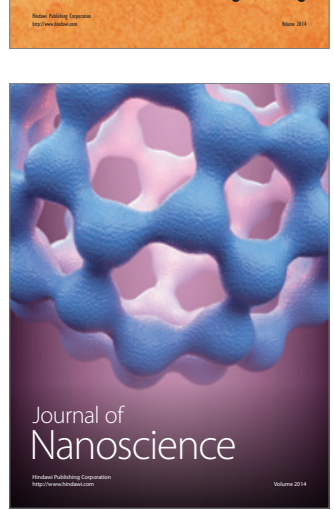
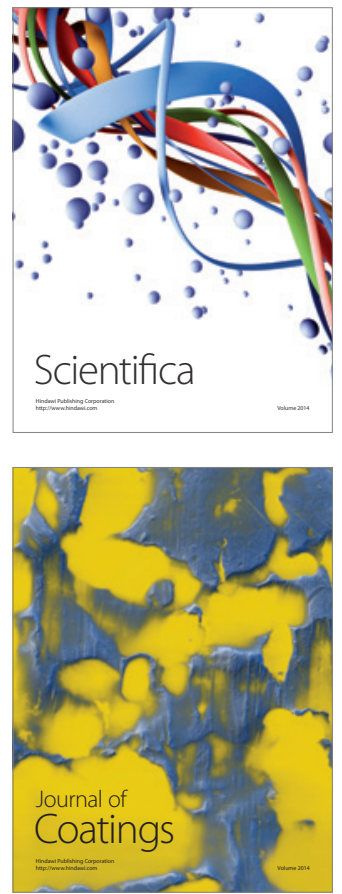
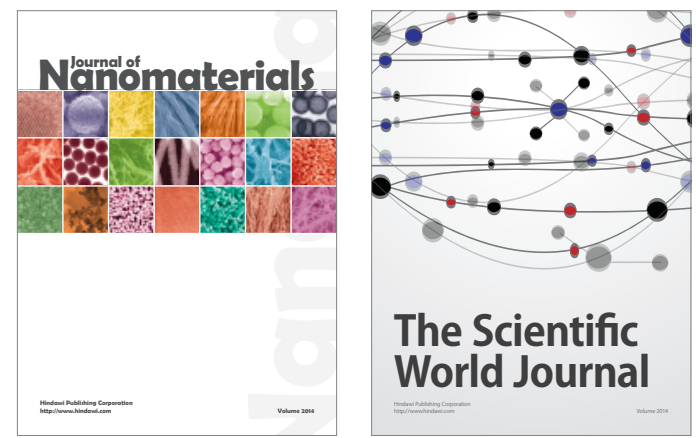

The Scientific World Journal
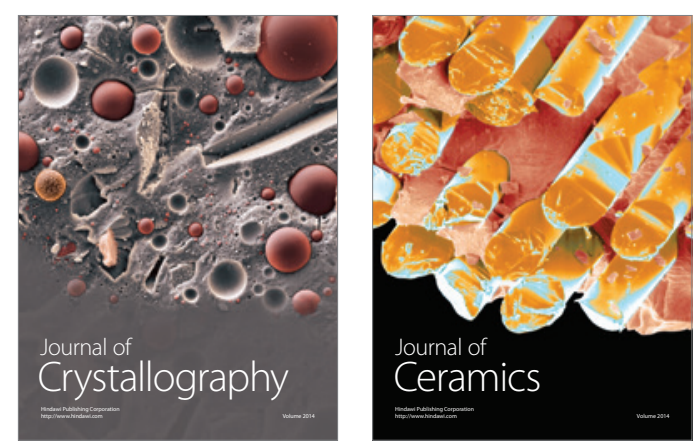
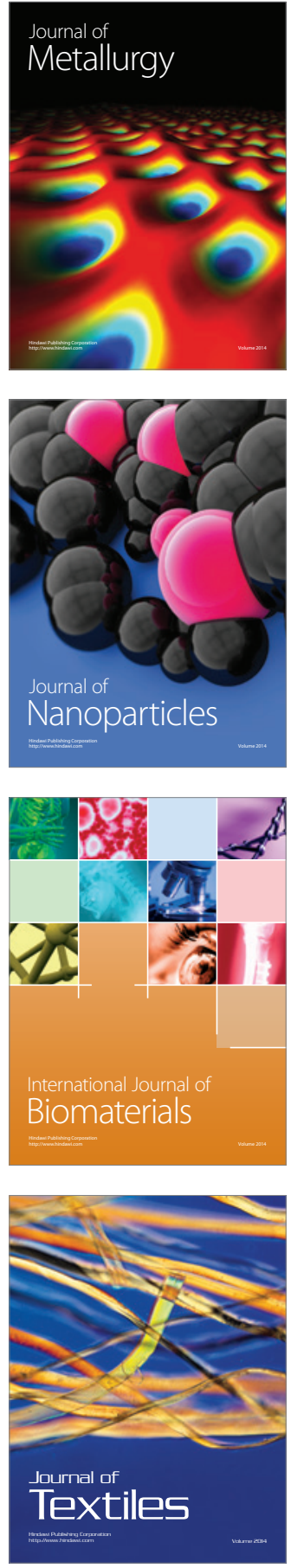